\title{
OTRA VUELTA DE TUERCA EL PATRIOTISMO CONSTITUCIONAL ESPAÑOL Y SUS MISERIAS
}

Xacobe Bastida Freixedo

Universidad de Oviedo

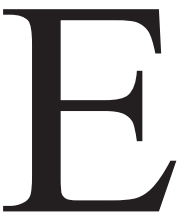

ste trabajo tiene como objeto denunciar una impostura. Lo cual implica que habrá que mostrar dónde está la impostura y en qué consiste la denuncia. La tesis básica es la siguiente: el patriotismo constitucional español (el que construye el discurso político y académico en España) no tiene nada que ver con el patriotismo constitucional en su formulación habermasiana -hasta aquí la impostura- a pesar de que sus mentores, por motivos interesados e ideológicos, intenten traer causa de ésta -hasta aquí la denuncia-. Antes de transitar todo este camino, y con el fin de facilitarlo, es conveniente comenzar con labor de desbroce. Hagamos un poco de teoría.

El concepto de nación incorpora, constitutivamente, dos pulsiones contradictorias que habrán de explicar muchos de los malentendidos y falsas controversias del debate acerca del nacionalismo. En efecto, la nación posee, ya desde su irrupción en el ámbito de las Ideas, dos momentos; el uno tiende a lo particular, el otro propende a lo universal. El primero valora lo distintivo e incluye dentro de sí todo aquello que sirve de elemento de integración y de cohesión en el grupo. Puede parecer paradójico que la valoración de lo distintivo y la integración sirvan conjuntamente para delinear un mismo contorno. Sin embargo, no es así. Y ello porque el concepto fundamental que maneja este momento es el de identidad. La identidad, como ha subrayado Hobsbawm (1994: 5), se desenvuelve en un contexto de referencia negativo. La identidad tiene siempre como elemento determinante la concesión de prioridad indiscutible a una concreta pertenencia característica construida sobre la exclusión de todos aquéllos que carecen de este estigma que es considerado pertinente para establecer la cesura entre dos o más categorías que, o bien resultan incompatibles, o se encuentran en relación de subordinación, pero que, en cualquier caso, jamás tienden a la conmixtión, pues en su misma génesis radica el antagonismo esencial que 
las caracteriza. La construcción tipológica a que da lugar el concepto de identidad, entonces, se plasma conforme a un patrón proyectivo que dibuja su sombra a la vez que se yergue. Nosotros, decimos para caracterizarnos como parte de un grupo -y esto nos identifica-. Nos, los otros, debiéramos decir para resaltar que esa identificación se da siempre a costa de una diferenciación. La integración, entonces, se produce por distinción. Desde esta perspectiva, la identidad, igual que la conciencia -conceptos que, por cierto, están mutuamente implicados- tienen una dimensión, que nos perdone la cohorte analítica, genuinamente dialéctica.

El otro momento característico de la nación, el que valora lo común, predica la igualdad entre los considerados nacionales; esto es, reconoce la relación paritaria de los -a partir de ahora llamados- ciudadanos. Ciertamente es este momento el que define a la nación como concepto moderno; es su estigma fundacional. Si prescindimos de él y nos ceñimos al primero de los momentos nos encontraremos con un concepto lisiado y, en cierta medida, mentiroso. Como cualquier concepto que surge al hilo de una evolución histórica, la nación es resultado de fenómenos previos, pero también adelanto de resultados nuevos. Si sólo vemos la nación como producto -que sin duda es- de la necesidad de cohesión intergrupal nos perderemos lo específico que de hecho tuvo su surgimiento e incumpliremos aquella máxima de Marx, don Carlos le llamábamos nosotros, que afirmaba el cambio de cualidad que se experimentaba con un cambio de cantidad. Ciertos enfoques historicistas caen en esa perversión (A. Hastings 2000) y con ello ven en toda agrupación y sentimiento comunal el origen de la nación. En Mesopotamia no había lucha de clases por la sencilla razón de que no había clases -lo que no quiere decir que no existiese explotación-; entre los kwiatl no existe aprovechamiento de la plusvalía, no porque no haya gente que se sirva del resultado del trabajo ajeno, sino, sencillamente, porque en su mundo no existe nada que se pueda englobar como trabajo asalariado. La interpretación de todo acontecimiento como protofenómeno de una estructura posterior que sirve para explicarlo es un resabio de la metafísica hegeliana, muy cara a los marxistas, que sirve para ajustar un afán teleológico no siempre inocente -un ejemplo de esta metodología torticera y providencialista la encontramos en España frente a Europa, de G. Bueno (1999)-. La componente democrática que incorpora el concepto de nación -es nacional todo aquél que está sometida a unas mismas leyes, decía Sieyés- no es un simple añadido a un sentimiento de cohesión comunitaria, sino que representa un giro conceptual, un corte epistemológico, por decirlo con Bachelard, que debe ser tenido en cuenta.

Claro que el error inverso, el que hace de este momento igualitario el único representativo de la nación, olvida que los conceptos ni surgen de 
la nada, ni operan en el vacío. De la misma forma que Ihering denunció a aquéllos que veían en el derecho un simple orden de paz -omitiendo que, genéticamente, el derecho implicaba una lucha constante-, aquí se advierte contra el despropósito que significa omitir la parte funcional -aunque irreflexiva- del concepto de nación y que viene dada por el sentimiento de pertenencia a un colectivo. Nos preguntamos si, conjuntamente, la conversión del primer dato cohesivo en un rasgo axiológico, y no meramente ontológico -tal hace el comunitarismo- y la omisión de ese dato mismo, acentuando hiperestésicamente el segundo -ese es el cuño de los llamados liberales- han impedido el desarrollo de un debate sano acerca del concepto de nación. Pero no tenemos por qué elegir entre el providencialismo y la amnesia. Aunemos las dos notas y digamos que la nación es una solución nueva de un problema viejo.

El Hombre, desde el siglo IV antes de Cristo lo hemos escuchado, es un animal político, un animal social. Pero esa propensión natural del hombre necesita cauces para poder canalizar lo que en principio es sólo pulsión instintiva. El Hombre precisa de instituciones que den forma a esa tendencia integradora. Ese es el problema viejo. El totemismo, las fratrías, la religión o la nación, son instituciones que han intentado solucionarlo. En efecto, en lo que toca al paralelismo con la religión y como pone de manifiesto Durkheim (1993), la sociedad crea a los dioses no para adorarlos, sino para adorarse a sí misma por mediación de aquéllos: "Si se borra de las mentes individuales la idea de la sociedad, si las creencias, las tradiciones y las aspiraciones de la colectividad dejan de ser sentidas y compartidas por los particulares, la sociedad morirá (...) La divinidad sólo tiene realidad en la medida en que ocupa un lugar en las conciencias humanas, y ese lugar somos nosotros quienes se lo otorgamos" (1993: 550). Los dioses no pueden prescindir de sus fieles. El fenómeno religioso no es, como pretendió cierta literatura marxista, una narcosis crónica con la que la humanidad habría delirado durante milenios. El culto religioso tiene por efecto la recreación periódica de un ser moral que depende de nosotros tanto como nosotros dependemos de él. Nos referimos a la sociedad. Pues bien, la nación opera de igual forma. Se construye la nación por idéntica necesidad de recreación social. Todos los ritos que encarnan la construcción nacional ponen en movimiento a la colectividad y los grupos se reúnen para celebrarlos. Su primer y más importante efecto es acercar a los individuos, multiplicar y hacer más íntimos los contactos entre ellos para hacer así posible la acción conjunta. Ésta es la verdadera relación entre la religión y la nación -el ser vehículos de cohesión- y no, como suele afirmar la beatería socialdemócrata, el que ambos conceptos sean un nicho de pensamiento metafísico en el que yacen 
la superchería, el fundamentalismo, la violencia y la intolerancia (F. Ariel del Val 1993: 40-41; J. Ma Bandrés 1988: 72).

Pero, a la par de su socialidad, el Hombre tiene también una pulsión disgregadora: desafía constantemente las reglas por las cuales se rige la comunidad -esto es, el Hombre es también un animal profundamente antisocial-, y por ello precisa de instituciones de legitimación. Aquí la nación incorpora un elemento novedoso, cual es el predicado de radical igualdad entre sus miembros. Tanto las llamadas teorías liberales de la nación -o francesas, o modernistas u occidentales, según el autor que elijamos- como las románticas -o germanas, o primordialistas, u orientales- han reconocido este factor como el determinante de la delimitación nacional, aunque, desde luego, lo han engastado de diferente manera en el seno de sus construcciones teóricas. Siguiendo el paralelismo que hemos establecido previamente, la integración que procede de la religión, y en contra de un lugar común bastante extendido hoy entre cierta intelectualidad que ve en la igualdad trascendente de las almas un embrión igualitario que luego eclosionará en la democracia actual, no presupone la igualdad de sus miembros sino a un nivel teológico, metafísico. La igualdad religiosa es igualdad ante dios, no igualdad política o social. Por el contrario, la institución nacional, que surge tras la periclitación de la legitimación monárquico religiosa y que cubre el espacio político que aquélla deja vacante, afirma la igualdad de los sujetos que la componen. No en vano la nación aparece como portadora de la soberanía. El contexto de pertenencia que antes era definido con criterios prepolíticos queda sustituido por una comunidad democrática de voluntad basada en la igualdad que genera el estatus ciudadano.

Así pues, para tratar cabalmente sobre el concepto de nación se precisa conjugar los dos elementos que constitutivamente han sido determinantes de su aparición: el integrativo y el legitimador igualitario. Ambos están en pugna, pero se necesitan mutuamente. Muchos autores han destacado esta genealogía dúplice de la nación que intenta conjugar los elementos básicamente irracionales de la identificación comunitaria con los factores racionalistas de la legitimación igualitaria. Habermas está entre ellos.

En efecto, Habermas habla de dos elementos que conforman el plexo de la institución nacional. El primero, al que denomina conciencia nacional, es una magnitud prepolítica caracterizada por la creación de vínculos solidarios basados en datos indisponibles a la voluntad del hombre. Es, en palabras de Habermas, "un fenómeno de integración cultural” (1998: 621) que suple a la red de lazos de tipo estamental establecidos previamente. La tradición, la lengua la cultura y el destino histórico compartidos serán los factores que le sirvan de aglutinante. En efecto, para Habermas, en línea con los autores que A. Smith (1976) denomina modernistas -el ejemplo más 
destacado e influyente es el E. Gellner (1988)-, el nacionalismo es una forma específicamente moderna de identidad colectiva. Tras la ruptura con el Ancien Régime, y con la disolución de los órdenes tradicionales de las primeras sociedades burguesas, los individuos se emancipan en el marco de las libertades ciudadanas abstractas. La masa de los individuos así liberados se torna móvil, no sólo políticamente como ciudadanos, sino económicamente como fuerza de trabajo, obligados al servicio militar y también culturalmente sujetos a una educación escolar obligatoria que aprende a leer y a escribir y se ven arrastrados así por el remolino de la comunicación y la cultura de masas (Habermas 1989: 89).

El segundo, el elemento que Habermas llama mentalidad republicana, es aquel que aparece con la Revolución Francesa y que opera sobre la base de la conciencia nacional transformándola en un tipo de identidad política de cuño democrático. Así, la nación de ciudadanos que produce la mentalidad republicana encuentra su identidad no tanto en rasgos comunes de tipo étnico-cultural como en la praxis de ciudadanos que ejercen activamente sus derechos democráticos de participación (Habermas 1998: 622). Nótese que no existe enfrentamiento fundacional entre estos elementos, tal pretende gran parte de la literatura que aborda el nacionalismo basándose en un Renan mal entendido -sirva de ejemplo A. Finkielkraut (1990)-, sino un aprovechamiento del primero por el segundo. No es posible que surja una mentalidad republicana -un reconocimiento de la igualdad subyacente en todos los ciudadanos- sin que previamente haya existido un modelo que, lejos de operar con la sola idea de pertenencia a una organización funcionalmente especificada, incida en que la autonomía política es un fin en sí que nadie puede realizar solo, persiguiendo privadamente sus intereses, sino que ha de realizarse por todos en común mediante la vía de una praxis compartida intersubjetivamente (Habermas 1998: 627). Como en tantas ocasiones en el terreno de las ideas, no se construye ex novo, sino aprovechando cimientos que ya han demostrado su solidez: "El nacionalismo mediado por la conciencia histórica y por el romanticismo (...) fundó una identidad colectiva que resultó funcional para el papel de ciudadano surgido en la Revolución Francesa (...) lo uno se convierte en vehículo del nacimiento de lo otro" (Habermas 1998: 623); "La invención del pueblo-nación tuvo un efecto catalizador para la democratización del poder estatal, pues una base para la legitimación de la dominación política no hubiera surgido sin conciencia nacional" (Habermas 1997: 176). De la nacionalidad adscrita propia de la conciencia nacional pasamos a la ciudadanía adquirida, democráticamente constituida. Claro que este paso, como queda dicho, no representa una absorción de la conciencia nacional por la mentalidad republicana. Ambos elementos se "entrejuntan y ensamblan" sin que por ello podamos hablar 
de mixtificación: "El Estado nacional había fundado, pero sólo transitoriamente, una estrecha conexión entre ethnos y demos. Pero conceptualmente la ciudadanía fue desde siempre independiente de la identidad nacional" (Habermas 1998: 623). De hecho, la mayor parte de los conflictos que hoy genera la cuestión nacional -sobre todo desde un punto de vista teórico- surgen de un enfrentamiento entre ambas componentes de la nación.

En situaciones de normalidad la instancia integrativa y la legitimadora se compenetran. El problema surge cuando una de ellas adquiere una preeminencia excesiva. El exceso en la conciencia nacional desemboca en el fundamentalismo autocomplaciente; el énfasis en la mentalidad republicana puede conducir a una fragmentación social que haga inoperante a la sociedad misma. En palabras de J. M. Rosales, “todo orden político para mantener su credibilidad, cualquiera que sea su signo, no puede prescindir del respaldo legitimador de la lealtad patriótica de sus súbditos o ciudadanos" (1997: 52). Pues bien, el problema que denuncia Habermas (1989: 90; 1991: 225) en la Alemania finisecular es que el latido patriótico que refleja el deseo de poder político de la nación -la conciencia nacional- ha anulado el otro factor de construcción nacional que afirma la libertad y la autodeterminación política cristalizadas en la democracia -la mentalidad republicana-. En Alemania, desde 1848, "el nacionalismo ha venido medrando a costa del republicanismo (...) Se ha convertido en un mofletudo y cachazudo nacionalismo de marco alemán” (Habermas 1991: 226, 289).

Para conjurar una situación tal y ante la inminente reunificación de Alemania -lo cual implica la creación de un discurso nacional que genera a la nación misma (X. Bastida 1998: 151 y ss.)- Habermas propone, recogiendo la definición de D. Sternberger un patriotismo de la constitución para equilibrar ambas componentes. Este patriotismo constitucional consiste en la creación de un sentimiento de pertenencia a una comunidad asentado sobre la adhesión a los valores democráticos y el respeto a los derechos humanos que recoge la Constitución. Conviene resaltar que los dos conceptos de la construcción obedecen a la necesidad de recuperar paritariamente aquellos dos elementos característicos de la formación nacional: se habla, por un lado, de patriotismo para recoger la conciencia nacional y, por otro lado, se habla también de constitución para asimilar la mentalidad republicana. De la misma forma que Habermas propugna una conjunción entre soberanía popular y derechos humanos para establecer un criterio de legitimidad política (2000: 150) -es decir, una mezcla de la irracionalidad latente en la tiranía del número y de la racionalidad subyacente en el reconocimiento de ciertos valores objetivados- se propone aquí una construcción similar en la que se alterna lo emotivo y lo racional como partes indispensables para lograr una legitimidad del sentimiento nacional. Se trata de armonizar la "nación naci- 
da" que opera de elemento de integración social y la "nación querida" que actúa como factor de legitimación democrática (Habermas 1997: 178-179).

Comoquiera que la conciencia nacional concentrada "en el amor de la patria y a la lengua materna, en la cohesión prepolítica del pueblo alemán” (Habermas 1991: 226) había adquirido una preponderancia sobre el elemento republicano, al punto de que el mensaje del universalismo de las libertades iguales para todos y del igual respeto por todos se había convertido en una "abstracción exangüe", se hace necesaria una construcción que, sin perder la capacidad aglutinante de lo primero, haga hincapié en esto segundo. Y esto no sólo por la componente democrática que incorpora, sino porque, en el caso alemán, fundar un nacionalismo apoyado exclusivamente en la conciencia nacional -en los datos que proporciona la historia y la tradición- resulta especialmente complicado. La "confianza ingenua en las propias tradiciones" (Habermas 2000: 46) no es posible allí donde, por mor de la memoria más reciente, la ingenuidad es sinónimo de cinismo monstruoso o de directa complicidad. El recuerdo del "bárbaro lado nocturno", el intento de superar las "dos dictaduras alemanas" (Habermas 1989: 94; 1997: 71), propician el intento de creación de una identidad política posnacional que se disocie del trasfondo de un pasado explicado en términos de Historia nacional y que se centre en el "contenido universalista de una forma de patriotismo cristalizada en torno a los principios del Estado constitucional democrático" (1989: 94). De esta manera es posible alejarse del compromiso con una conciencia histórica que no puede servir de fundamento a convivencia alguna, pues permanece ciega a la profunda ambivalencia de toda tradición. Así las cosas, y en aras de una "normalización alemana" (Habermas 2000: 44), Habermas estima la posibilidad de establecer un patriotismo de la constitución en la República federal basándose en la "disponibilidad a identificarse con el orden político y los principios constitucionales" (1989: 94) como solución a la complicada formación de una identidad alemana que ha de prescindir de la referencia al pasado por constituir éste un baldón en la memoria histórica que forzaría una ruptura radical con el continuismo representado por la versión tradicional de la comunidad.

En suma, lo que propone Habermas es construir un concepto de nación alemana de raigambre eminentemente politicista -en el sentido de libre adhesión a ciertos valores (X. Bastida 2002: 135 y ss.), no en el sentido bárbaro que le imprime A. de Blas $(1984,1989)$ y con él la práctica totalidad de los, soi dissant, teóricos españoles del nacionalismo- alejado de la fundamentación basada en razones objetivas y en tradiciones incuestionadas.

Hasta aquí la exposición sucinta de las claves de la teoría del patriotismo de la constitución habermasiana y del ámbito en el que se desarrolla. Veamos ahora la pertinencia o no de su importación a nuestros lares. 
Porque es lo cierto que, en España, sobre todo a partir de una ponencia del Partido Popular en su XIV Congreso (2002) -aunque desde luego, en el plano académico ya había sido introducido antes- el patriotismo constitucional se ha instalado en el debate político y en la terminología publicística. Hoy ya es un concepto pacífico del que el españolismo parte para aclarar su postura ante la cuestión nacional. Llama la atención que la reivindicación del Partido Popular del patriotismo de la constitución no ha despertado en la práctica totalidad de los partidos de la oposición sino un juicio crítico acerca de la "patrimonialización" del concepto por parte de los populares. Esto es, todos hacen suya la doctrina habermasiana, lo único reprobable es que alguien la adopte como teoría partidista cuando debiera ser, al parecer, logro colectivo.

La importación de una construcción tal ofrece ventajas indudables. Para empezar, se recaba el argumento de autoridad. Algo que, por otra parte, no es nuevo en estos menesteres de la construcción nacional. Allá por 1978, en pleno debate constitucional acerca del problema de las nacionalidades, un artículo periodístico de M. García Pelayo en el que criticaba la utilización del concepto de nacionalidad en el artículo $2^{\circ}$ fue utilizado de manera indiscutida -tal era su prestigio- por los constituyentes para aclarar la interpretación auténtica, en el sentido jurídico, de dicho concepto. Aquí, de igual modo, la mera alusión a Habermas -auténtico filósofo de guardia al que acudir en todo avatar occidental; qué más da, don Friedrich, que dios haya muerto si ya tenemos a Habermas- proporciona una garantía de éxito argumentativo -algo que, dicho sea de paso, contravendría las reglas procedimentales del discurso habermasiano-. En segundo lugar, la construcción es especialmente apta para lograr una solución de compromiso. La alusión a la patria satisface los apetitos del nacionalismo españolista tradicional -la patriótico, dirá por todos Sánchez de León (1978: 162), nunca puede ser reaccionario- que ve en el término la recuperación de un espíritu muy caro a su linaje. Pero, al tiempo, la alusión a la Constitución provee a los nacionalistas españoles más moderados del bálsamo con el que aliviar su prurito retrógrado, pues la Constitución -quien no la vea así no está en este mundo, o al menos en este Estado- es sinónimo directo de convivencia, pluralismo, tolerancia, etc. La Constitución cede parte de su maiestas democrática a una Patria que, do ut des, fortalece emotivamente a la Constitución. De esta forma se le lava la cara al patriotismo y se matricula en un gimnasio a la Constitución. Limpio y musculado, nuestro concepto ya puede lucirse en el mundo de la política. En tercer lugar, la coyuntura histórica en la que surgió en Alemania el patriotismo de la constitución era extremadamente parecida a la actual situación en España. En ambos países -en España es una cuestión atávica, es parte de nuestro folclore político- se planteaba la cuestión acerca de la mejor 
articulación nacional. También en ambos países el nacionalismo de Estado había dejado una memoria sangrienta, de tal modo que intentar fundar una nación sobre su pasado y su tradición era, en terminología penalista, una tentativa inidónea. El optimismo universalista, por decirlo con P. Gomberg (1994: 536), de la construcción habermasiana y la delicadeza con la que soba al pasado son características que propiciaron su adopción.

Ahora bien, nada de lo dicho hasta ahora constituye una crítica propiamente dicha. Simplemente se ha aludido a la proximidad de situaciones reales, a la utilidad que representa una solución de ese calibre y a la garantía que en última instancia representa la solvencia de la paternidad teórica. Nada hay de malo en importar una teoría foránea. Como decía Ortega, el casticismo es un barbarismo en la dimensión temporal. Lo que sucede es que no se ha importado con certificado público de compra: el patriotismo de la constitución se ha introducido de contrabando, no ha pagado las tasas de la crítica y, como suele pasar en estos casos, la mercancía ha llegado defectuosa. De hecho sólo ha llegado la carcasa. Veamos ahora lo que se ha quedado por el camino.

En primer término, la relación con el pasado que establece la teoría de Habermas y su sucedáneo hispano no es la misma. El filósofo alemán, en la conocida "polémica de los historiadores", intermedia entre el seguimiento ciego de la tradición y la moralización autocomplaciente (2000: 45) acudiendo a la memoria crítica: "No podemos buscarnos nuestras propias tradiciones, pero sí que debemos saber que está en nuestra mano el decidir cómo podemos proseguirlas (...) Pues toda prosecución de la tradición es selectiva, y es precisamente esta selectividad la que ha de pasar hoy a través del filtro de la crítica, de una apropiación consciente de la propia historia" (1989: 121). Con el patriotismo de la constitución la identidad colectiva encuentra sus límites en los postulados de universalización de la democracia y los derechos humanos, pero no se renuncia a la forma de identidad nacional formada a través de la conciencia histórica: "El mismo contenido universalista habrá de ser en cada caso asumido desde el propio contexto histórico y quedar anclado en las propias formas culturales de vida. Toda identidad colectiva, también la posnacional, es mucho más concreta que el conjunto de principios morales, jurídicos y políticos en torno a los que cristaliza" (1989: 118-119). Así pues, aunque el patriotismo constitucional ha de nutrirse forzosamente de la herencia de la tradición cultural -"las tradicionales nacionales siguen acuñando todavía una forma de vida que ocupa un lugar privilegiado" (Habermas 1989, 102)- debe cambiar el punto central de la legitimación colectiva: necesita pasar de su situación en la conciencia e identidad nacionales a una sede más abstracta, la de la universalización de 
la democracia y de los derechos humanos. Es ahí donde deben refractarse los rayos de las tradiciones nacionales de la propia nación.

La clave de la memoria crítica parte de la necesidad de pasarle cuentas a la historia y a la tradición. Si tradición significa la prosecución aproblemática de algo que otros han iniciado y hecho por nosotros, se precisa un contraste crítico que opere a modo de beneficio de inventario generacional. En opinión de Habermas, la tradición no adquiere legitimidad por el hecho de transmitirse generacionalmente; no cabe consistencia en esa transmisión y no puede acreditarse por la certificación de ese pedigree traditivo. Lo contrario sería una lamentable confianza antropológica que, en el caso de Alemania, quedó destruida con la cámara de gas (1989: 113). La memoria es pues necesaria. Pero no basta con eso. La comprensión de un fenómeno no ha de confundirse con la asunción del mismo. Por eso Habermas también se alerta ante una exposición puramente narrativa de los sucesos históricos y patrocina una explicación teorética y racional de los mismos. La explicación lineal, positivista, de la historia corre el peligro de desembocar en un "desagravio gratuito" (Habermas 2000: 44). En efecto, la distancia acrítica y en principio objetiva que el historiador adopta al respecto de la realidad pasada redunda en una especie de pesimismo antropológico fatalista que, lejos de servir como patrón de enjuiciamiento de los hechos, los absuelve. La consideración "científicamente distanciada" pasa por una supuesta neutralidad que "pretende colocarse lisa y llanamente en la situación de los participantes con el fin de entender a los actores y sus acciones a partir de su propio contexto" (Habermas 1989: 112), con lo que se pierde de vista el entramado de relaciones, el "plexo fatal" del período en su conjunto. En palabras de Habermas, "el modo que tenemos de afrontar las cuestiones de imputación de responsabilidades no depende sólo de los hechos, sino también de nuestra forma de mirar estos hechos" (2000: 54). No existe inocencia en la mirada. Más aún, es la forma de mirar la que determina tanto lo observado como la atalaya del observador: "la forma en que, en esa mirada retrospectiva a la historia, veamos distribuida la culpa y la inocencia refleja también las normas según las cuales estamos dispuestos (...) a respetarnos mutuamente" (2000: 54). En suma, los dos elementos que conforman esa memoria crítica son, en primer lugar, la recuperación del pasado -esa es la memoria-y, en segundo lugar, la actualización del pasado mediante una visión de conjunto -esa es la crítica-.

Pues bien, estos dos elementos son eludidos -bien conjuntamente, bien cercenando uno de ellos- por la aplicación política española del patriotismo de la constitución. A la hora de afrontar la relación con el pasado -y esto es algo que nace en el proceso constituyente de 1978- se prefiere el olvido ignominioso de la historia más reciente -pues ignominiosa fue esa historia- en 
aras de una reconciliación nacional, de un sano enterramiento de odios que desunen más que enlazan, de un apaciguamiento de sentimientos viscerales que nos alejarían de la concordia... Por eso -esa es la estrategia favorita de la derecha por razones obvias, aunque no es la única en adoptarla- se prefiere construir el nuevo sentimiento patriótico con base en la amnesia, en la ineptitud de la tabla rasa. A esto responde la negativa sistemática del PP a la hora condenar parlamentariamente el golpe franquista, el cicatero reconocimiento de los derechos de los militares republicanos, las trabas a cualquier tipo de investigación que intente certificar los desmanes cometidos en las represalias de la posguerra, la generosidad política con la que se trata a ciertos personajes que se acostaron fascistas y con las manos manchadas de sangre y se levantaron demócratas e impolutos, etc. Por decirlo con términos de la ponencia "El patriotismo constitucional”, leída en el XIV Congreso del PP y debida J. Piqué y M $\mathrm{M}^{\mathrm{a}}$ San Gil, "las nuevas generaciones no se merecen que esos nuevos retos [democráticos] sean abordados con viejas ideas, con viejos prejuicios y agravios, con viejas historias". Una vez enviado el pasado al geriátrico nada obsta para una construcción nacional con la lozanía de lo impúber. Enterremos odios, es la consigna. Emblema de un cinismo insoportable si tenemos en cuenta que fueron los odios de los indultados por obra y gracia del olvido munífico los que sirvieron para enterrar a mucha gente. Así pues, la memoria habrá que dejarla para los opositores a notaría y alejarla de la construcción del sentimiento cívico ciudadano.

Por otra parte, la faceta crítica del pensamiento de Habermas también es mutilada. Y ello porque en las pocas ocasiones en las que se acomete un ajuste de cuentas con la Historia -muy concretamente con el período franquista- los personajes parecen pasar por ella con una especie de inocencia de autómata, como si lo que hicieron no fuera fruto de una voluntad, sino servidumbre de una inercia política. Ese es el peligro de la empatía que denuncia Habermas (1989: 112; 1991: 211 y ss.; 2000: 46) -antes lo había hecho G. Lukács (1968)- que acecha siempre en ese estilo puramente narrativo de la historia. Claro que esta visión naif de la historia, curiosamente, sólo suele ser aplicada cuando se trata de justificar a los vencedores, a los que han prevaricado con éxito, a los impostores triunfantes. Porque la otra faceta de la mutilación de la memoria consiste en el recuerdo distorsionado y avieso de los esfuerzos del antifranquismo. J. I. Lacasta ha dedicado un capítulo de su excelente libro España Uniforme a criticar esta estrategia y a él me remito (1998: 262 y ss.). La indulgencia y permanente contextualización con la que se trata al pensamiento filofascista no tienen lugar cuando se trata de los personajes que lo combatieron. Aparecen en este último caso acusaciones constantes -e injustas- de stalinismo, fundamentalismo marxista, totalitarismo, etc. En palabras de Lacasta, esta actitud "es el producto de 
un fenómeno más vasto que se caracteriza por la sistemática destrucción de la memoria antifranquista, por una mutilación cultural, se mire por donde se mire, de nuestra propia historia que es -o debería ser- patrimonio de toda la ciudadanía española (...) Y la deformación de lo acontecido no es el menor servicio de la "corrección" española a la amnesia colectiva del antifranquismo” (1998: 281). Así pues, frente a la recuperación crítica del pasado que propone Habermas nos encontramos aquí bien con un olvido crónico, bien con un recuerdo interesado y acrítico. Pero, confiemos en los clásicos: Memoria capta feros victores cepit. Tal vez llegará el momento en que la memoria vencida se apodere de sus vencedores.

En segundo término, el sustrato real de la ciudadanía en relación con la cuestión nacional no sólo no es la misma en Alemania y España, sino que es opósita por diámetro. Esto es, la realidad sociológica en la que se inscriben uno y otro patriotismo es antagónica. En la Alemania previa a la unificación de 1989 existía un acuerdo social acerca de la necesidad de unión en torno de una misma constitución -"una expresión inequívoca de la voluntad nacional de reunificación” (Habermas 1991: 225)-. De hecho, en un sentido estricto, en Alemana no existía cuestión nacional, si por esta expresión entendemos las discrepancias que surgen en un Estado acerca de qué se considera una nación. Los desacuerdos existentes estaban relacionados con el tipo de unión, no con la unión misma, ni con la consideración nacional uniforme que se alcanzaría con dicha unión. Cosa muy otra acontecía y acontece en España. En el estado español -y esto se puso de manifiesto ya desde los debates constituyentes y se confirma periódicamente en las elecciones autonómicas y en el debate político cotidiano- no existe una voluntad unánime en lo tocante a la unidad nacional. Que España sea Una nación y que los ciudadanos del Estado español se consideren integrantes de esa nación -ese era el presupuesto sociológico en Alemania- es una idea nada pacífica (en muchos sentidos) por nuestros lares. En efecto, la nación española entendida como correlato del Estado no suscita una adhesión tal que permita hablar del consenso ideológico necesario para establecer una conciencia nacional común -y ya vimos cómo la conciencia nacional operaba de sustrato en la mentalidad republicana-. Por decirlo con la terminología de G. Mosca (1982: 192-193), la unidad nacional de España no es parte de la fórmula política, esto es, no se integra en el arsenal de doctrinas y artículos de fe reconocidos por todos e incuestionados en la sociedad y que son necesarios para legitimar la necesidad de gobernar y requerir obediencia. $\mathrm{O}$, por utilizar esta vez la teorización de Habermas (1988: II, 178), la unidad nacional no se incluiría entre las significaciones sociales que consolidan y cohesionan a la sociedad; no formaría parte del mundo de la vida, de ese conjunto de convicciones de fondo aproblemáticas, de esos supuestos y prejuicios pre- 
rreflexivos que todo miembro del grupo social supone garantizados y desde el cual se forma el contexto de los procesos de entendimiento. En síntesis, mientras que en Alemania la unidad nacional era uno de los presupuestos de legitimación de toda acción política, en España era, y es, un impedimento de esa legitimación.

En tercer término, y esto está directamente vinculado con el punto anterior, la articulación del patriotismo constitucional se concibe de manera opuesta en la versión de Habermas y en su importación hispana. Y ello por dos motivos. El primero incide en el diferente carácter asignado a la voluntad en el proceso de formación nacional. El segundo en el entendimiento del concepto de constitución al que se alude en la construcción "patriotismo de la constitución". Vayamos por partes.

El patriotismo constitucional habermasiano maneja el concepto de nación política y desemboca en la defensa de un nacionalismo cívico. Por nación política hay que entender -para no caer en ciertos despropósitos teóricos- toda aquella nación que utiliza como clave fundamental de construcción nacional la voluntad de los miembros que la componen -y no toda aquella nación que parta de la preexistencia de un Estado, como pretende la doctrina dominante-. A la inversa, por nación cultural hay que entender toda aquella nación que se sirve de elementos objetivos, ajenos a la voluntad de los miembros de esa nación, para lograr la construcción de la nación -y no toda aquella nación que carezca de Estado y aspire a él-.

Pues bien, si esto es así, decía, la teoría de Habermas se inscribe claramente en la línea politicista, en aquélla que incidía en la voluntad de los miembros como elemento determinante de la definición nacional. Con un tenor un tanto evangélico dice Habermas que "la República sufre quebranto si la fuerza integradora de la nación se hace derivar de algo dado prepolíticamente, de un hecho independiente de la formación de la voluntad política. Una nación naturalizada de esta suerte, tiende a neutralizar y eliminar por vía de homogeneización las contingencias históricas en la composición de la comunidad consolidando y dotando así del aura de lo de siempre y de lo cuasi-natural a los límites que a esa comunidad le acontece contingentemente tener" (Habermas 1997: 179). Esto es, si pretendemos tomar en serio la mentalidad republicana -aquel elemento que, recordémoslo, sirve de legitimación democrática a la nación- es necesario incluir la voluntad política de los miembros de la nación e impedir el concurso de factores que, previos al acuerdo ciudadano -dados prepolíticamente, dice Habermas- y escudándose en la fatalidad de lo histórico por vía de su asimilación a un proceso natural, determinen el devenir de la construcción nacional. "Sólo entonces, continúa Habermas, puede la idea republicana cobrar primacía y penetrar y 
estructurar, a su vez, las formas de vida que aseguran la integración social" (1997: 179).

El papel de la voluntad en la forja del patriotismo de la constitución genuino se muestra claramente cuando Habermas trata del proceso de unificación de las dos Alemanias. En este caso "la alternativa no es "doble estatalidad" o "anexión", sino orientación sin reservas por el objetivo de una democratización radical que deje la decisión a aquellos que han de correr con las consecuencias, o instrumentalización de la retórica de la autodeterminación para una política de anexión impulsada con los medios de una política exterior de tipo económico" (1991: 227). Por eso es indispensable que sean "los ciudadanos de la República Democrática los que decidan en elecciones libres si quieren pasar a formar parte de un futuro Estado alemán unitario" (1997: 228); por eso se precisa que, lejos de dictar arbitrariamente y desde arriba las condiciones y estructura de la futura Alemania, "se conceda una oportunidad a cualquier camino que los ciudadanos de la República Democrática quieran emprender por libre decisión" (1991: 229).

La voluntad, pues, se constituye en la clave de bóveda del arco patriótico habermasiano. Algo antitético, como se verá, a lo que ocurre con su aplicación en España. Y es que, tanto en los debates constituyentes de 1978 que crearon la actual concepción de la nación española como en el texto de la Constitución misma, aparecen sin ningún género de duda elementos que anulan la operatividad de la voluntad de los ciudadanos en la configuración del ámbito de lo nacional. Es cierto que en los debates constituyentes, en un primer momento, aparecieron conatos de fundamentación política, voluntarista, de la nación española. Adoptando la teoría orteguiana del "proyecto sugestivo de vida en común" y de la "nación como empresa" parecía que era posible llegar a una concepción democrática de la nación, a una "nación querida", en la terminología de Habermas. Sin embargo, cuando en la Cámara se planteó la posibilidad de reconocer la plurinacionalidad del Estado español y, en consecuencia, se puso sobre el tapete el reconocimiento del derecho de autodeterminación, apareció el verdadero sentir de los constituyentes. Las anteriores intervenciones que exaltaban las "empresas comunes", "la voluntad de vivir juntos" o la "libre voluntad de los pueblos de España" se diluyeron por ensalmo y dieron paso a manifestaciones que reducían lo anterior a pura fraseología. La unidad de la nación española parecía estar en peligro con la entrada de la posibilidad del plebiscito y por eso se anula el concurso de la voluntad ciudadana. Que España era una -Una- nación -Nación- era un presupuesto que no podía ponerse en entredicho. Por eso, ahora, la nación ya no se define de manera política sino de forma que su esencia se haga indisponible a la voluntad de los asociados. España pasará a ser una unidad forjada por la Historia, por el destino histórico -concepto que es 
tildado por Habermas, recordémoslo, de "muleta prepolítica" (1991: 308)-, por algo, en definitiva, indisponible e irreformable. "La unidad de España es un valor para nosotros [UCD] metaconstitucional y preconstitucional; la Constitución puede asumirlo, proclamarlo, reconocerlo [...] lo que no podrá es fundamentar ella, la Constitución, a esta unidad" (Cisneros Laborda, TP, 1980: 849, I); "Damos por sentado [PSOE] que España, como nación, existe antes de la Constitución. Para nosotros la nación como hecho relevante es derecho preexistente a la Constitución (G. Peces-Barba, TP 1980: 846-851, I), "Y es claro que la Constitución no puede echar los cimientos o fundamentos al edificio que es España, porque España es una magnitud extensiva e intensiva que se sustrae a toda regulación constitucional. España era antes, y será después de esta Constitución, una entidad permanente (M. Herrero de Miñón TP, 1980: 849, I).

Lo que la Historia ha hecho que no lo deshaga el Hombre. "España, decía un Solé Tura que antes se hubo desgañitado con peanes voluntaristas, no es una invención, no es un artificio histórico, es una realidad forjada por la Historia" (TP, 1980: 724, I). De la misma manera, M. Herrero de Miñón podía decir que "es la Historia, la vieja Historia la que ha decantado una nación española que no podemos concretar, que no podemos reducir al marco de la Constitución"; o Silva Muñoz afirmar que "la Nación española es la resultante (...) de un todo armónico con un único destino que cumplir, unidad superior de vida común" (TP, 1980, 1900, II); o M. Fraga aseverar que el único criterio para concretar la esencia de España era el de apreciar "la comunidad de un largo destino histórico (...) El concepto de nación no se puede acuñar a voluntad" (TP, 1980, 1879, II; 658, I). La nación española, en suma, pertenece al género de los hechos brutos, como diría J. Searle (1997), esto es, la nación española existe con independencia de la voluntad y el acuerdo humano, es un hecho que, en su realidad y estructura, se nos impone querámoslo o no. Incluso cuando se mencionaba la voluntad como elemento conformador de la nación aparecía, presta, la corrección historicista: "Llamamos Nación española a la voluntad histórica decantada de vivir juntos como españoles (...) Los diferentes pueblos de España se autodeterminarán una vez más como su estructura histórica exige, como la unión de su variedad" (M. Herrero de Miñón, TP, 1980, 2531, II). Es curioso ver cómo la Historia, por definición campo de creación, como diría Castoriadis, se ve aquí constreñida por el cíngulo de la incontingencia. Puede que existan voluntad y autodeterminación, pero ambas han de estar predeterminadas como "su estructura histórica exige". Por eso, cuando se habla de España como realidad histórica, en verdad se quiere decir "realidad inamovible", "realidad natural" o "realidad necesaria". Mucho nos tememos que también se quiera decir "realidad revelada". Si comparamos todo esto con aquel pá- 
rrafo ya citado de Habermas en el que criticaba los procesos de construcción nacional que operaban "por vía de homogeneización de las contingencias históricas en la composición de la comunidad, consolidando y dotando así el aura de lo de siempre y de lo cuasi natural a los límites de esa comunidad" (1997: 179) nos percataremos de la imposibilidad de asimilar la concepción habermasiana de nación que da lugar al patriotismo constitucional a la que se ha consolidado en España. Lleva razón J. I. Lacasta cuando afirma que "lo que ocurre es que el nacionalismo español es culturalmente débil, democráticamente inconsistente; porque resulta a ojos vista insuficientemente constructivo y no se presenta más que como algo que impide, que destruye que niega" (1999: 24).

Esto en lo que respecta al discurso nacional. Pero también en el propio texto constitucional es perceptible una mutación fundamental entre la teoría del patriotismo de la constitución que se invoca y lo que la Constitución de 1978 ofrece. En efecto, como vimos, Habermas se alertaba contra la posibilidad de que "la fuerza integradora de la nación se hiciese derivar de algo dado prepolíticamente" (1997: 179). Esto es, para la mentalidad republicana, democrática, resulta fundamental que la transformación de los afectos que surgen de la conciencia nacional de pertenencia -los afectos "prepolíticos"- pasen por el tamiz de la voluntad política de los ciudadanos. Y esto es algo radicalmente negado en el texto del artículo $2^{\circ}$, al punto de que es una realidad pre-constitucional, esencialista, la que fundamenta la Constitución y no a la inversa, como en principio se predicaría de un ordenamiento que, sobre la base de la libertad de decisión ciudadana, intentase una fundación nacional instituyente. Recordémoslo: "La Constitución se fundamenta en la indisoluble unidad de la Nación española..." (Art $2^{\circ} \mathrm{CE}$ ). En este caso es la indisoluble unidad de la nación española la que actúa de marco prepolítico que conforma lo jurídico -lo que ha posibilitado que una buena parte de la doctrina, sirva como ejemplo el trabajo de J. Ruipérez (1995: 128 y ss.), haya podido hablar de la unidad de la nación como un límite implícito a la reforma constitucional-. Aquí sólo existe conciencia nacional que absorbe la posible emergencia del elemento republicano. La voluntad de los miembros de la nación no entra en juego: la indisoluble unidad nacional es previa y fundamentadora de esa voluntad que, por tanto, ya no es libre -no es voluntad-. Por eso, cuando J. J. Laborda afirma que "España, con el acto constituyente de 1978, decidió ser una nación o una patria común” (1992: 9), está falseando los datos. Podemos discutir acerca de interpretaciones, pero no se discute acerca de datos. Y lo cierto es que con el acto constituyente de 1978, mediante un ejercicio de reflexividad inverosímil, la Nación española -concebida como sustrato previo a la Constitución- decidió ser una Nación española o patria común. 
Dice Laborda, citando palabras que Habermas pronunció en una conferencia en el Instituto de Filosofía del CSIC, que el patriotismo de la constitución "es una identificación común con una comunidad histórica fundada sobre ciertos valores. Pero debe tratarse de una comunidad cuyos valores centrales incluyan la libertad" (1992: 5). Pues bien, si esto es así, entonces no se comprende cómo, a renglón seguido, puede espetarnos que "en la Constitución de 1978 este patriotismo, en mi opinión, está recogido y definido en el artículo segundo" (1992: 6), a no ser que la razón esgrimida sea que en ese artículo se menciona la palabra Patria y está en la Constitución -razón, por otra parte, accesible a un perro de Pavlov-. Porque si de libertad hablamos, habrá que incluir también -máxime si nos referimos al art. $2^{\circ}$, en el que no se trata de ninguna definición de derechos individuales, sino de definiciones de carácter institucional colectiva- la libertad de los ciudadanos que pertenecen a las nacionalidades reconocidas para decidir cuál será su adscripción nacional, algo que es negado de forma tajante en la formulación del artículo $2^{\circ}$. La libertad individual y la colectiva -no otra cosa trata de conectar Habermas al hablar de mentalidad republicana y conciencia nacional- necesitan ser conjugadas.

Los hombres, como ha subrayado MacCormick $(1994,66)$, son productos sociales, no átomos independientes capaces de constituir una sociedad por medio de un encuentro voluntario: "Estamos hechos por nuestra sociedad, como también la sociedad está hecha por nosotros. Los hechos biológicos del nacimiento y de los primeros alimentos, así como los hechos psicosociales de nuestra educación y socialización son esenciales para constituirnos como personas. Somos las personas que somos de acuerdo con los marcos y contextos sociales en los que llegamos a ser tales personas (...) Tenemos conciencia de nosotros mismos por el modo en que hemos aprendido a ser nosotros mismos en nuestro contexto". Siguiendo en esto a Y. Tamir (1993, pp. 32-34), todos los individuos forman parte de lo que pudiéramos llamar "individuos contextuales". El hombre sólo existe en la sociedad y por la sociedad. Los sujetos, los individuos y sus grupos son los productos de un proceso de socialización y su existencia presupone, ab initio, una sociedad instituida (C. Castoriadis, 1998a, p. 157 y ss.; 1998b, p. 64y ss.). Parece entonces que la polémica entre el comunitarismo y el liberalismo es, desde el punto de vista ontológico, absurda. Las concepciones individualistas, atomistas, de las que parte la visión liberal de la sociedad no son ni siquiera criticables. Son mucho más que eso: son falsas. Su punto de partida, el que los hombres tengan un estatuto racional-individual a partir del cual se enjuicia la pertinencia de la adscripción a una determinada comunidad, describe incorrectamente la incardinación del Hombre en la Sociedad. Ahora bien, el reconocimiento de la corrección comunitarista en la descripción del hecho 
social no implica que su juicio normativo acerca del papel de ese hecho social sea igualmente correcta. La anulación más o menos explícita de la autonomía individual a la que conducen ciertas teorizaciones comunitaristas -es el caso de Ch. Taylor (1992, p. 25 y ss.)- resulta insostenible. Pero hay que tener claro que este juicio de disvalor se desarrolla en una dimensión axiológica, no ontológica. La realidad y los corolarios de esa realidad son cosas que deben ser distinguidas, y el debate actual del comunitarismo y del liberalismo las confunde penosamente.

Ahora bien, el que hayamos dicho que el liberalismo era una teoría falsa no significa de ningún modo que sus postulados sean erróneos. Ya apuntamos que su dimensión propia era la axiológica. De este modo, reconocer la virtualidad explicativa de lo social no implica rechazar cualquier forma de individualismo normativo. Está claro que el nacionalismo se deslegitima éticamente cuando, por excluyente o por impositivo, se contrapone a la lógica inclusiva de la democracia (Pérez Tapias, 2000, p. 84). Como afirma MacCormick, "puedo no creer que los individuos se conciban como átomos pre-sociales o extra-sociales, cuyas uniones llegan a constituir sociedades, y tener, al mismo tiempo, bastantes motivos para creer que debemos favorecer formas de organización dentro de las cuales los seres humanos puedan constituirse y florecer como individuos autónomos" (1994, p. 67). Es más, precisamente porque creemos que el individuo precisa de autonomía -en el sentido pleno de la palabra, en el kantiano, que es el que intenta recuperar Castoriadis- nos parece necesario el reconocimiento de la realidad nacional. Nuestra conciencia de la identidad proviene de nuestra experiencia de pertenecer a comunidades significativas cargadas de intencionalidad colectiva. El sujeto no existe sino como el resultado de los condicionamientos que proporcionan estas determinaciones contextuales. A partir de aquí, a partir del reconocimiento de la determinación histórico cultural del sujeto, podemos hablar ya de lo que las teorías liberales llaman "individuo autónomo" -que sólo será relativamente autónomo-. La sociedad es el presupuesto, el punto de imputación esencial para la forma en que el individuo da sentido a su vida económica, moral y política. Pues bien, si esos individuos autónomos son el resultado del contexto de una sociedad que los capacite para la libertad, entonces la autonomía colectiva de la sociedad misma parece una parte del contexto necesario (N. MacCormick, 1994, p. 67). Mientras el Estado permanezca separado de la sociedad civil y de sus significaciones simbólicas sólo existirá una autonomía parcial de los individuos. La democracia emocional, que es precondición de la democracia política, precisa la unión del poder político y la significación simbólica de la sociedad misma. Si concebimos la autodeterminación -entendida desde un punto de vista genérico (kantiano)- como un bien necesario para la libertad, debe existir tanto 
un dominio propio para la autonomía del hombre dentro de la colectividad -extremo éste sobre el que insiste, con razón, la teoría liberal- como un dominio propio para la autonomía colectiva de la comunidad -y sobre esto la teoría liberal calla ignominiosamente-.

El respeto a la autonomía de la persona se ha entendido siempre como la preservación de un campo de obrar autónomo, libre de injerencias. Y, al tiempo, ese respeto ha sido el punto de inflexión de la filosofía de la ilustración, hoy reivindicada como superación del escepticismo y relativismo postmodernos. Ambos asertos son, en lo esencial, correctos. Lo que ocurre es que el liberalismo ilustrado de nuestros días sólo concibe a la persona desde una perspectiva individualista, monádica. Muy al contrario, por el hecho de mantener que el imperativo moral básico es el respeto a la persona -integral- aquí sostenemos que la conciencia de la nacionalidad es para las personas algo parcialmente constitutivo de su conciencia de la identidad y, por tanto, que el respeto de ese aspecto de su identidad es tan vinculante como el respeto de cualquier otro aspecto. Tanto, por ejemplo, como el respeto a la libertad de expresión. Un ataque a esta libertad es capaz de movilizar a la intelectualidad toda; el derribo sistemático de los marcadores de identidad nacionales es, sorprendentemente, motivo de regocijo y alharaca universalista por parte de esa misma intelectualidad.

Y lo cierto es que, lejos de reconocer la virtualidad democrática del principio nacional -y escudándose en el carácter reaccionario de ciertas construcciones comunitaristas- la Academia asimila el nacionalismo a la antítesis de la libertad, de los derechos humanos y de la democracia, siendo así que la verdadera democracia presupone la existencia del nacionalismo -de la conciencia nacional, en la terminología de Habermas- como principio ontológico. Los derroteros actuales de la investigación no sólo prescinden del tratamiento de la democracia en la formación nacional, sino que identifican como nacionalistas -connotadas, por supuesto, con todo tipo de características aberrantes-, sólo a aquellas formaciones que impugnan a la realidad estatal como fuente de legitimación.

Tras lo dicho ha de quedar claro que en el artículo $2^{\circ}$ no hay lugar ni para la libertad colectiva, ni para la democracia. Se podría hablar de verdadera patria común si se hubiese establecido un procedimiento en el que las partes nacionales que son reconocidas por la misma Constitución, pudiesen expresar su voluntad libérrima de pertenencia al todo nacional. Nos referimos al derecho de autodeterminación, expresamente planteado por Euskadiko Ezkerra en el debate constitucional y rechazado de manera igualmente expresa por el resto de la Cámara -alegando, por cierto, el consenso logrado en el artículo $2^{\circ}$-. Este artículo, entonces, no puede ser fundamento de ningún patriotismo que tenga como base el valor de la li- 
bertad que, según Habermas, es necesario para poder hablar de patriotismo constitucional. Por otra parte, en el proceso de formación del artículo $2^{\circ}$ tampoco existió auténtica libertad en su elaboración, pues fue impuesto -y redactado- por el poder militar (J. Solé Tura 1985, 99; X. Bastida 1998: 43 y ss.). Así pues, estamos ante un texto en el que no intervino la libertad en su redacción y cuya redacción no deja lugar para la libertad. No obstante, esa es la opinión de la doctrina dominante y, desde luego, el punto de partida de nuestros patriotas de la constitución que hablan sin rubor del artículo $2^{\circ}$ de la Constitución como un "gran pacto histórico de la transición democrática" que muestra "la voluntad de todos para encontrar un marco en el que podamos sentirnos razonablemente cómodos" (Piqué y San Gil 2002: 2-4), el artículo $2^{\circ}$ pasa por ser la piedra de toque de lo que Habermas llama patriotismo constitucional. Conviene no confundir las cosas. Lo que sí existe es un patriotismo español que surge de la Constitución, pero no es de cuño habermasiano. Precisamente por su interés acendrado en la unidad patria y su beligerancia con los partidarios de una concepción politicista de la nación basada en el reconocimiento del derecho de autodeterminación, la filiación del patriotismo constitucional español ha de buscarse en las corrientes conservadoras -tanto las tradicionalistas como las genuinamente fascistas- que han transitado por el cauce histórico del Estado español. Algunos podrán decir -J. Álvarez Junco (2001), entre otros, lo dice- que su estirpe habría que entroncarla con el liberalismo español. Algo de cierto hay en ello. Ocurre, sin embargo, que el liberalismo español en materia de construcción nacional -de esto no se salvan ni Unamuno, ni Ortega, ni el mismísimo Azaña (este último dependiendo del auditorio al que se dirigiera, pues, para despistar a sus adversarios, al igual que las gallinas pampeanas, solía pegar el grito en un lado y poner el huevo en el otro)- estaba muy próximo a las líneas conservadoras antes mencionadas.

Pero, decíamos, en la articulación del patriotismo de la constitución de Habermas y en su versión española no sólo existe una diferencia fundamental en el papel que se otorga a la voluntad ciudadana, sino también en el concepto mismo de constitución que se maneja. En efecto, cuando Habermas habla de la constitución como foco del patriotismo se refiere a los postulados de universalización de la democracia y de los derechos del hombre que se encuentran en las constituciones occidentales (Habermas 1989: 114). Si hay algo que debe unir a los ciudadanos de manera emotiva, si hay algo que debe ligarlos en la defensa de su comunidad, ese algo habrá de ser, primordialmente, producto de los principios universales, de los procedimientos y de los derechos abstractos recogidos en la constitución (Habermas 1997: 72). Así pues, la constitución se concibe como el refugio de la mentalidad republicana que asegura que los motivos de cohesión surgidos en principio 
de la conciencia nacional se depuren mediante un crisol universalista. La constitución es sinónimo aquí de valores sustantivos -de reconocimiento de los derechos humanos como núcleo básico de unión- y de procedimientos discursivos que hagan posible la democracia. Como resume N. López Calera, el patriotismo de la constitución habermasiano está basado en una "identidad nacional fundada en la lealtad común con los procedimientos democráticos y con los derechos fundamentales" (1995: 74)

Muy al contrario, en el patriotismo constitucional hispano, la constitución de la que se habla equivale no a ningún valor sustantivo, sino al documento formal mismo. Esto es, tanto la parte dogmática de declaración de derechos como la partes dedicadas a la organización institucional -incluyendo, por supuesto, la unidad del Estado y la monarquía- son objeto del patriotismo. Lejos de considerar la constitución como punto de encuentro de la mentalidad republicana, se parte de ella para generar una conciencia nacional -españolista-. Los procedimientos que, según Habermas, se recogen en la constitución como método discursivo de resolución de conflictos y que deberían integrar el núcleo del patriotismo constitucional no tienen lugar en la Constitución de 1978. Y ello precisamente porque en materia de construcción nacional el artículo $2^{\circ}$ impide el concurso de procedimiento discursivo alguno -algo que quedaría garantizado con el reconocimiento del derecho de autodeterminación: aquí sí aparece el cauce correcto por el que pueden fluir las reglas del discurso-. En lo que toca a los valores materiales que en principio asegura la adhesión a una constitución no creemos necesario insistir sobre lo dicho más arriba. En la Carta Magna del Estado español, y en lo que respecta a la cuestión nacional, no caben ni la libertad ni la democracia, habida cuenta de la interdicción de la voluntad ciudadana para decidir acerca del modelo de nación en el que se desea vivir.

Por eso, creemos que no lleva razón J. I. Lacasta cuando afirma que "si España no es producto -como piensa García Trevijano- "de una decisión voluntaria de sus pobladores", el "patriotismo" que de esta guisa la defienda será cualquier cosa menos constitucional" (1999: 7). Si tenemos en cuenta que la Constitución de 1978 está fundamentada en la preexistencia de la indisoluble unidad de la nación española (art. $2^{\circ}$ ) y que el derecho de autodeterminación está absolutamente prohibido (arts. $2^{\circ}, 8^{\circ}$ y $145^{\circ}$. 1 ), el aserto de Trevijano es directa traslación del juicio constitucional en la materia. En efecto, el concepto de nación que se ha constitucionalizado no es producto de una decisión voluntaria de sus ciudadanos, sino reflejo de una unidad preexistente a la formación de la voluntad ciudadana. Por ello, el patriotismo que emane de esta visión -que es antivoluntarista, culturalista y prepolíticaserá muy, pero que muy constitucional. Lo que no será es democrático. 
En un sentido inverso, llama la atención la enemiga de García Trevijano a la articulación nacional derivada del artículo $2^{\circ}$ de la Constitución. García Trevijano es uno de los autores que con más ahínco ha insistido en la negación de la voluntad ciudadana como factor determinante en la definición de la nación española. España es una realidad objetiva que no se puede hacer y deshacer mediante la voluntad del pueblo: "España, como las demás naciones, no ha sido el fruto de una decisión voluntaria de sus pobladores, renovada día a día en una especie de "plebiscito de 24 horas", como decía Renan (1994: 23)". Y esto que García Trevijano afirma es exactamente lo que la Constitución consagra en su artículo $2^{\circ}$. Por eso sorprende su crítica a la "licencia concedida al Estado para modificar a su antojo la base nacional y el hecho histórico de España" que, a su parecer, se permite en la Constitución. El peligro que García Trevijano observa en la supuesta desvirtuación constitucional de la concepción objetivista que él mantiene no es tal. Cuando este autor afirma que "hay cosas que nos vienen dadas sin libertad, como el oxígeno del aire que respiramos (...) y una de esas cosas es la nación" (1994: 16) está reproduciendo la argumentación objetivista y culturalista, negadora de la voluntad de los individuos a la hora de la construcción nacional, que fuera utilizada en la fundamentación del artículo $2^{\circ}$ de la Constitución y finalmente reflejada en el mismo. El enemigo que combate García Trevijano es en realidad aliado. Por otra parte, el patriotismo de la Constitución basado en el artículo $2^{\circ}$ no representa en modo alguno ese "grave daño causado a la nación" por cuanto posible amenaza a su integridad, ni es un "sentimiento bastardo que ha suplantado (...) el sentimiento español de patria" (García Trevijano, 1994: 16), sino que es, en consonancia con lo que mantiene el autor, auténtico garante de la sagrada unidad nacional y baluarte en absoluto espurio de la concepción patriótica de España, en el sentido más tradicional del término. De hecho, el artículo $2^{\circ}$ de la Constitución introduce el concepto de Patria y remarca la idea de unidad hasta extremos grotescos. En suma, García Trevijano atribuye al patriotismo de la Constitución las funesta consecuencia que supone el "que se pueda seguir decidiendo, en nombre de la libertad, sobre asuntos históricos excluidos de la voluntad de los gobiernos" (1994: 16), cuando, en realidad, la función del patriotismo constitucional, en España, es la inversa. La indisponibilidad de la materia nacional no es contradictoria con el patriotismo constitucional hispano, es su acicate.

Por eso, el patriotismo constitucional ha encontrado en nuestros pagos un aliado de valor inestimable en el constitucionalismo -en la Teoría del Estado constitucional-, aunque también, como veremos, con peculiares matices que distorsionan el cariz de la teoría. En términos generales, el constitucionalismo es una teoría que considera no solamente que la constitución integra una serie de preceptos de carácter jurídico, y por tanto vinculante, 
sino que, además, postula un entendimiento valorativo de la misma. De esta manera, las opciones políticas adoptadas por la constitución se convierten en principios de carácter moral que deben informar la interpretación de la legislación subyacente y, correlativamente, modelar una articulación concreta de la sociedad civil. Una sociedad compleja como la actual, se dice, necesariamente dividida en estrategias particulares de poder, necesita un denominador común, un núcleo de valores compartidos que impida que el predominio de un grupo implique la anulación de los legítimos intereses de otros. Para evitar la tiranía de, en palabras de Zagrebelsky (1995: 25), "los señores de la ley" -de la Asamblea soberana que pudiera estar dominada por una facción- es preciso encontrar una "parte fija", un "contenido esencial" que asegure la convivencia de los distintos intereses en liza sin que ninguno de ellos se vea postergado a la marginalidad. Así pues, dos son las claves que caracterizan el constitucionalismo. La primera es la existencia de un conjunto de valores recogidos en la Constitución que deben garantizar el pluralismo y sobre los que debe existir una convergencia social. En la Constitución no sólo habría normas de conducta obligatorias, sino pautas de convivencia que actuarían de patrón comunitario. La sociedad, viene a decir la teoría constitucionalista, precisa de una actitud de compromiso hacia ciertos valores que se encuentran en los principios constitucionales. La segunda es -y ello deriva directamente de lo anterior- la indisponibilidad que ese conjunto de valores tiene para el legislador. De lo que se trata, en última instancia, es de sustraer al legislador ciertas materias que se consideran de especial importancia y formar un "núcleo estable e irreformable", en palabras de K. Hesse. Por utilizar la terminología del derecho civil, ciertas partes de la constitución se transforman en bienes extra comercium. Pues bien, el constitucionalismo del que se echa mano en España distorsiona la primera de las claves y, eso sí, lleva al extremo la segunda, ya que se propugna la intangibilidad de los pilares fundamentales del edificio constitucional "en cuanto que fundamentos de orden de la comunidad" (J. Ruipérez 1995: 128) y entre los que se incluye, por supuesto, la unidad de la nación española. Veamos el tenor de la distorsión.

Para Zagrebelsky, el Estado constitucional debe ser "dúctil”. Con esta imagen pretende compendiar los términos de coexistencia y compromiso que, a juicio de este autor, deben delinear las constituciones de los Estados contemporáneos. Esto es, la Constitución representa el punto de partida consensual, el momento incondicional -por utilizar el cuño habermasiano- en el que todos los ciudadanos encuentran un lugar común desde el que desplegar sus diferencias. En estas constituciones "la visión de la política que está implícita no es la de la relación de exclusión e imposición por la fuerza (en el sentido de amigo-enemigo hobbesiano o schmittiano), sino la inclusiva de 
integración a través de la red de valores y procedimientos comunicativos" (Zagrebelsky 2001, p. 15). A juicio de Zagrebelsky el único contenido sobre el que una ciencia de la Constitución pluralista ha de mostrarse intransigente es precisamente el de la defensa de la pluralidad de valores y principios. La Constitución ha de mantener abiertas sus posibilidades y condiciones de existencia y no cerrarlas abrazando enteramente las perspectivas de algunas de las partes. De este modo, la coexistencia posible de contenidos ha de constituirse en el núcleo inamovible de la Constitución (Zagrebelsky 2000: 16-17). La concepción hispana del patriotismo de la constitución se opone radicalmente a esta consideración. En el artículo $2^{\circ}$ de la Constitución española, el texto que, al parecer, enuncia nuestro patriotismo constitucional, se realiza una operación estrictamente inversa. Si tenemos en cuenta que los valores que aquí están en juego son los propios de la convivencia nacional, el artículo en cuestión cierra en lo absoluto todos los cauces de discusión y consagra la ratio nacional de una de las partes en liza. La función de mantener unidas y en paz sociedades divididas en su interior y concurrenciales -este es el objetivo básico del constitucionalismo- es radicalmente trastrocada. El artículo $2^{\circ}$ de la Constitución española es un punto de desencuentro entre las diversas concepciones de lo nacional. Por eso disentimos abiertamente de A. de Blas cuando asegura que en la Constitución española se asigna "no la tarea de establecer directamente un proyecto predeterminado de vida en común, sino la de realizar las condiciones de posibilidad de la misma. Desde la Constitución, como plataforma de partida que representa la garantía de legitimidad para cada uno de los sectores sociales, puede comenzar la competición para imprimir al Estado una orientación de uno u otro signo, en el ámbito de las posibilidades ofrecidas por el compromiso constitucional" (A. de Blas 2001: 13). Si el pluralismo ideológico en el que se hace consistir al constitucionalismo pasa por consolidar una "convergencia general sobre algunos aspectos estructurales de la convivencia política y social que puedan, así, quedar fuera de toda discusión y ser consagrados en un texto indisponible" (Zagrebelsky, 2000, 40), no podemos sino afirmar que en la Constitución de 1978 este pluralismo ha sido excluido. Si seguimos la argumentación de Zagrebelsky, "la Constitución pluralista presenta la estructura de un pacto en el que cada una de las partes implicadas introduce aquellos principios que se corresponden con sus ideales de justicia. De este modo, dichos principios vienen rescatados del ámbito de lo prejurídico e insertados plenamente como tales en el derecho" (2000: 97). Nada de esto ha ocurrido en el proceso constituyente. A pesar de la fraseología armonicista de cuño predominantemente orteguiano -aunque también se echó mano de Tönnies, Meinecke y Krause- con que se aderezaron las intervenciones parlamentarias que justificaron este artículo, no ha habido pacto, sino imposición; no 
ha habido introducción paritaria de principios, sino injerto de un principio monolítico. Sorprende por ello que M. Herrero y Rodríguez de Miñón -no sabemos hasta qué punto ingenuo y bienintencionado o cínico y torticeroseñale que "el buque de la flexibilidad constitucional necesaria para encajar la plurinacionalidad española es sumamente difícil de botar: déjesele alcanzar el mar sin lastre excesivo" (1998: 12). El buque de la "flexibilidad" -sólo tras descabellada antífrasis podemos entender esta expresión- está diseñado para permanecer sine die en las atarazanas del Estado. Malamente puede navegar lo que no está ideado para ello. Lo que es más: malamente puede navegar lo que no existe. Porque, conviene no olvidarlo, la flexibilidad es a la Constitución lo que la elasticidad es a la piedra pómez.

Esta es la distorsión a la que nos referíamos más arriba. El constitucionalismo, teoría ya de por sí criticable por lo que tiene de moralización implícita de la legislación y de reificación de las decisiones políticas (J. A. García Amado 1996; J. M. Rodríguez Uribes 2002; X. Bastida 2003), parte de un compromiso con ciertas cuestiones valorativas sobre las que existe un acuerdo fáctico, un consenso. El constitucionalismo en España no distingue esta cuestión y extrapola ese compromiso concreto a una fidelidad a la constitución in toto. Y, muy concretamente, basa el acuerdo subyacente en un artículo, el segundo, que representa justamente lo contrario a los valores compartidos e incuestionados en la sociedad española. El deslizamiento conceptual no puede ser más claro: "Defender la Constitución es defender los Estatutos de Autonomía (...); defender los Estatutos de Autonomía es defender con todas sus consecuencias la idea de España" (Piqué y San Gil 2002: 3); o, de modo aún más claro: “Constitución, España y libertad (...) son términos sinónimos” (2002: 6). La defensa de la constitución se hace pasar, pues, por la defensa de un artículo $2^{\circ}$ que, como sabemos, representa la imposibilidad de articular democráticamente la cuestión nacional en el Estado español. Por eso resulta falso afirmar, intentando quintaesenciar el patriotismo constitucional, que "lo importante es respetar los núcleos de convivencia: pluralidad, tolerancia, libertad; autonomía y unidad" (Piqué y San Gil 2002: 3). La autonomía -nos tememos que no se refieran aquí los autores al sentido kantiano del concepto- y la unidad no puede permanecer al lado de la pluralidad, la libertad o la tolerancia. Y ello porque la autonomía y la unidad, con la interdicción añadida de cualquier movimiento que las cuestione -véanse sólo a título de ejemplo las respuestas del Gobierno a las proposiciones no de ley de los parlamentos catalán y vasco en los años 89 y 90 sobre el derecho de autodeterminación o al Plan Ibarretxe en 2002 (con amenazas veladas de intervención militar en ambos casos)- suponen lo contrario del pluralismo, la libertad y la tolerancia. No se pueden equiparar principios que todo el mundo admite como base de la convivencia con de- 
cisiones político-territoriales que, en primer lugar, no todo el mundo asume $\mathrm{y}$, en segundo lugar, son contradictorias con los primeros. Y decimos que son contradictorias porque, aunque le pese a cierto sector de la academia, el artículo $2^{\circ}$ impide el concurso de la libertad ciudadana y, con ello, arruina la posibilidad de lograr una solución democrática -no sólo en el sentido habermasiano, sino en el del mismísimo Pericles- a la articulación nacional del Estado. Sin reconocimiento del derecho de autodeterminación no cabe hablar ni de procedimiento discursivo, ni de libertad, ni de tolerancia. Por eso llama la atención que, para A. de Blas, el patriotismo constitucional, "como punto de confluencia de una larga tradición de nacionalismo liberaldemocrático español" se encuentre recogido en la Constitución de 1978: "Creo que la Constitución de 1978 ofrece las bases para un acomodo de las lealtades nacionales en la vida española, en el marco de un reconocimiento plural de esas realidades nacionales. El sistema de valores que acompaña a ese reconocimiento, el principio de pluralismo, de tolerancia y de lealtades compartidas, ofrece el marco adecuado para la definitiva puesta al día de un discurso nacionalista español de signo democrático dispuesto a convivir y a llegar a acuerdos razonables con otros discursos nacionalistas de signo periférico..." (A. de Blas 2001: 59). Por eso sorprende también que J. J. Solozábal pueda decir que "La constitución como marco político es congruente con el nacionalismo no independentista (...) Y además, en cuanto sistema de reglas de juego limpio, es perfectamente compatible con el nacionalismo independentista" (2000: 15). En la cuestión que nos ocupa, las reglas de juego limpio han de posibilitar que todos los jugadores puedan sentarse a la mesa con la expectativa de ganar la partida sin tener que transgredirlas. Esto es, las reglas deben defender la posibilidad de que cualquier jugador pueda triunfar -lo que equivale a decir que los intereses a los que aspira se vean protegidos por esas reglas-. En este sentido, la Constitución debe proporcionar sólo un marco de posibles estrategias y procedimientos que faculten al jugador para poder optar entre ellas e intentar conseguir su meta en el juego. Como se ve, nada de esto es posible en la Constitución de 1978, pues reduce la timba bien a jugadores de ventaja que se saben favorecidos por ciertas suertes del juego, bien a jugadores que se ven forzados a ejercer de truhanes, belitres y malsines, siempre necesitados de trampas para poder conseguir su objetivo.

Hasta aquí hemos visto cómo el patriotismo constitucional hispano trastroca las claves de la teoría original habermasiana y envenena otras fuentes aledañas. La razón parece clara. La creación de un nacionalismo españolista $\mathrm{y}$, de manera consiguiente, la construcción de un antinacionalismo periférico, son las razones que guían al patriotismo constitucional. De la misma manera que en el período constituyente se utilizaron como expedientes la 
distinción teórica entre la nación política y las naciones culturales o el constructo Nación de naciones para así constituir un nacionalismo de signo español que combatiese la insurgencia de nacionalismos de signo competitivo, ahora, con nuevas armas, se intenta el mismo objetivo. Las claves estructurales siguen siendo idénticas a las que definían anteriores tentativas. Por una parte, comoquiera que el concepto de nacionalismo se ha demonizado para localizar terminológica y simbólicamente al enemigo, el movimiento panespañolista se desmarca de la intitulación nacionalista -"Nosotros no somos nacionalistas", afirman raudos (Piqué y San Gil 2002: 5)-. Por otra parte, como lo que realmente se pretende es crear un nacionalismo que sirva de antídoto a las pretensiones autodeterministas, no se duda en emplear todas las estrategias que funden un nacionalismo omniabarcante que las diluya. En suma, se trata de crear un nacionalismo sin que lo parezca.

Por esa razón lo que se recoge de la teoría de Habermas es únicamente su parte inmovilista mientras se anula el recurso a la voluntad ciudadana que aquélla también acoge. La fraseología democrática que se toma de Habermas -"el patriotismo constitucional es una adhesión crítica y moralmente exigente, es un sentimiento racionalizado y dotado de una fuerte brújula ética y moral..." (Piqué y San Gil 2002: 5)- no puede disimular el fondo de la cuestión, a saber, la construcción -a cualquier precio- de un nacionalismo españolista. De hecho, cuando se olvidan de las gollerías habermasianas y descaran sus argumentos, los patriotas de la constitución no dejan lugar a la duda. Así, cuando se refieren al nacionalismo de la periferia, "al que no tiene sentido" (J. Piqué y M. San Gil 2002: 5), hablan de un "nacionalismo excluyente que exalta la diferencia, es decir, el nacionalismo no constitucional" (2002: 5). Esto es, existe un nacionalismo que sí tiene sentido, que exalta la uniformidad -su máxima es E pluribus unum: del pluralismo a la unidad, siendo así que esta última es la explica al primero, concebido como una inocente floresta de anomalías toleradas- y que, por supuesto, es constitucional. Esto explica aquella distorsión comentada consistente en que el núcleo del patriotismo no esté formado por valores democráticos y procedimentales, tal y como postula Habermas, sino por la Constitución en conjunto. Se sabe que la Constitución, globalmente considerada, es nacionalista (españolista) y por eso se santifica y se convierte en un texto cuya interpretación "recuerda las lecturas que, por ejemplo, ciertos fundamentalismos islámicos hacen del Corán" (R. Vilar 2002: 50). Mientras que Habermas patrocina un nacionalismo cívico -un patriotismo moderado, en palabras de S. Nathanson (1989: 535 y ss.)- el patriotismo constitucional hispano sustenta un nacionalismo tradicional de corte objetivista.

Si alguien hablase de un "patriotismo de la nación" se le objetaría, con razón, que es una expresión redundante. Habermas rompe el pleonasmo 
precisamente porque el objeto del patriotismo va referido a una constitución concebida en términos universalistas y de respeto a los derechos humanos. Aquí, sin embargo y como ya nos consta, el patriotismo tiene como objeto un documento formal -la Constitución- que consagra un cierto tipo de nacionalismo. La redundancia no se obvia. El patriotismo de la Constitución, cuando la Constitución es nacionalista, equivale a patriotismo de la nación. Mejor: a patrioterismo de la nación. Qué alegría debió sentir la grey constitucionalista cuando Habermas habló por primera vez de patriotismo de constitución. Salvados. Se puede ser demócrata y reivindicar la patria. Se puede ser nacionalista español (patriota) y a la vez antinacionalista.

Por ello no compartimos la interpretación del patriotismo constitucional que realiza J. I. Lacasta. Cuando este autor habla de la necesidad de que el nacionalismo español "se mire al espejo", nos dice que, además de la cara irascible y sorda ante la voz jurídico política de los nacionalismos, reflejaría otra: "la del patriotismo constitucional, la de la Nación de naciones, el Estado multinacional (...), el Estado federal, y cuantas propuestas se apoyen en el reconocimiento de los principios del Estado democrático de Derecho y los derechos fundamentales" (1999: 44-45). Hay dos razones que nos mueven a la crítica. La primera es que, en realidad, esas dos caras que describe Lacasta son una y la misma cara. Sólo que la segunda, la faz del nacionalismo español democrático y atemperado, es la imagen fotogénica de la primera, que no deja de ser una horrible mueca. Dejemos que se relaje la cara amable del nacionalismo españolista -o, lo que es lo mismo, leamos entre líneas (y a veces ni eso, basta con leer literalmente) los trabajos de Savater, Juaristi, Unzueta, de Blas...- y veremos cómo se contraen sus facciones y aparece su desagradable visaje. Esto es, el nacionalismo panespañolista sólo tiene una, aunque mucha, cara. La segunda crítica es que muchos de los rasgos que Lacasta describe como característicos de ese nacionalismo españolista democrático -la sola expresión nos zahiere el oído- son facciones que no caben en la misma cara. Estado multinacional y Estado federal, por un lado, y Nación de naciones, por otro, son conceptos excluyentes. De hecho, en los debates constituyentes se utilizó el segundo como antídoto de los primeros. Cuando los diputados nacionalistas vascos expresaron en una enmienda la posibilidad de articular un Estado multinacional de carácter federal empezó a oírse en la cámara la voz Nación de naciones para justificar la Unidad indisoluble de España -la Nación- reconociendo, eso sí, la existencia de ciertas porciúnculas territoriales con cierta especificidad -las naciones-. Para evitar la existencia de un Estado federal en el que las partes -nacionales- formen un todo -estatal- (y de ahí lo de "Estado multinacional"), la nación de naciones se concibe como un todo unitario y previo que se distribuye analíticamente en partes. La nación de naciones tiene, pues, un signo marcadamente an- 
tifederalista. Y otro tanto cabe decir del patriotismo constitucional que de ningún modo ha de verse como un avance democrático del nacionalismo españolista, sino como una perpetuación de su tenor histórico. Desde el proceso constitucional de 1978 se ha intentado fundamentar la existencia de un nacionalismo español que no estuviera anclado en los factores objetivos tradicionales (raza, lengua, religión...) -lo que Habermas llamaría conciencia nacional-, sino que se afianzase en rasgos de inequívoco carácter democrático. Sabedores de las insuficiencias que presenta la historia del nacionalismo españolista, la militia legum se ha esforzado sobremanera en el intento de armonizar el sentimiento patriótico español con un ánimo cívico -y para ello ha utilizado expedientes de todo tipo: la desnaturalización del concepto de nación política para aplicárselo a la realidad del Estado español, la presentación de ese mismo Estado como Nación de naciones o como Estado federal in pectore, entre otros (X. Bastida 1998: 70 y ss.)-. El patriotismo constitucional no es sino el último de los eslabones de esta cadena de cohonestación.

En efecto, hay buenas razones para considerar que en la construcción patriotismo de la constitución de la que se hace uso en España no se intenta una síntesis entre el nacionalismo cívico y el étnico -como es el caso de Habermas o, utilizando otra terminología, el de M. Viroli (patriotismo republicano) o E, Gellner (religión constitucional) (Viroli 2000; 2001: 3 y ss.; Gellner 1994: 112)- sino una prolongación del nacionalismo étnico queremos decir con ello nacionalismo objetivista, cultural-. Aquí el término fundamental no es el de constitución entendida como reunión de valores democráticos, sino el de patriotismo -referido sobre todo, por cierto, a una parte de la Constitución en la que se consagra la Nación española concebida como patria: esto es, estaríamos ante un patriotismo de la patria-. Y el concepto de patria, como ha puesto de manifiesto P. Vilar, "añade al de nación la parte de irracionalidad" (1982: 233). En realidad, desde un punto de vista histórico los dos conceptos se han opuesto. Así, cuando en las Cortes de Cádiz de 1812 se propuso definir la nación española como "la reunión de los españoles de ambos hemisferios", el diputado Villanueva intenta añadir "baxo unas mismas leyes" -introduciendo así la moderna concepción de nación como libre reunión de súbditos en torno de un Estado-. A ello opone Capmany -el primero en hablar de España como Nación de naciones, conviene recordarlo- que sería mejor hablar de patria como "unión o comunión así como se dice comunión de los fieles y no la reunión de los fieles...”. Por utilizar la terminología de Tönnies, la sociedad que implica la nación se opone a la comunidad que representa la patria. La vinculación política a una colectividad por crear, proyectada en lo porvenir, se opone a la continuación del pasado, a las tradiciones, a las glorias comunes. 
Pues bien, el patrioterismo de la constitución recoge a Capmany y olvida a Villanueva. Es la patria como núcleo irracional -y como tal inamovible, exenta de posible discusión- la que prevalece frente a una nación española que pudiera concebirse como libre adhesión de diferentes pueblos. Por otra parte, el concepto de Patria se introduce en la actual constitución española a partir de las enmiendas de la derecha franquista, no lo olvidemos a la hora de hacer exégesis. Su sentido, tanto en la introducción constitucional como en las aplicaciones políticas que de él se hacen, no tiene nada que ver con interpretación democrática alguna, ni con la conformidad con unos principios jurídicos universales. Pero resulta que la patria -trágala mediante- ha quedado constitucionalizada y como la Constitución es "marco democrático de pluralidad y tolerancia", "núcleo de convivencia", "brújula ética y moral" (Piqué y San Gil 2002, 4-5) y, en suma, splendor veritatis, se precisa legitimar el concepto.

Por ello, para J. J. Laborda el concepto de patria, "no se corresponde con una mera exaltación lírica de símbolos y leyendas. Bien al contrario, la tesis que propongo lo vincula al sentido político y racional que, a mi juicio, posee, incluso históricamente" (1992, p. 5). Comoquiera que en todo el trabajo de J. J. Laborda no encontramos ni un sólo dato histórico que muestre esta vinculación racional y sí encontramos, en cambio, una glorificación del artículo $2^{\circ}$ de la Constitución, en el que, como nos consta, se introduce el concepto de patria, parece que nos encontramos ante un intento de cohonestación política más que de una opinión teórica. J. M. Rosales comparte esta misma visión legitimista -aunque en su caso lo que se pretende legitimar no es el artículo $2^{\circ}$, sino el concepto mismo de patriotismo de la constitución- y llega incluso a invertir la relación que aquí hemos establecido. Así, para este autor, "patriotismo y nacionalismo designan dos tipos de lealtad política a la forma de vida en común que conocemos bajo el nombre de vida civil. Sin embargo, mientras que la lealtad patriótica se funda en la experiencia de autoconstitución política de la comunidad de conciudadanos, la lealtad nacionalista lo hace sobre un sustrato de naturaleza pre-constitucional (...) Patriotismo y nacionalismo, como formas de lealtad cívica, determinan dos tipos de identidad colectiva, diferenciados por su remisión en el primer caso a un sistema constituido de instituciones civiles y, en el segundo, al fundamento, de naturaleza étnica o cultural, sobre el que se realiza la autoconstitución o autodeterminación política de una comunidad" (1997: 52-53). También A. de Blas participa de esta inversión y aconseja "reservar el concepto de nación para aquellas realidades étnico-lingüísticas, dejando el término patria para la descripción de las naciones con asiento en realidades estatales" (1992: 57-58). En E. Kedourie, que es el padre de la actual corriente antinacionalista, encontramos un teorización muy similar. 
Kedourie defiende la noción de patriotismo como el verdadero sentimiento a defender por parte de los ciudadanos de un Estado, al punto de recomendar como máxima cívica la de "amor por la patria, lealtad a sus instituciones y celo en su defensa" (1985: 56). Si este noble concepto se confunde con el nacionalismo -que es por definición corrupto, interesado e ideológico- se debe a que "la doctrina nacionalista se ha apropiado de estos sentimientos universales al servicio de una antropología y metafísica específicas" (1985: 56). La nefasta distinción entre naciones políticas y naciones culturales al menos si la utilizamos con las coordenadas clásicas- se reitera con este deslinde entre patriotismo y nacionalismo. De hecho la razón funcional de la distinción entre naciones políticas y culturales estriba en que, con ella, es posible que el Estado se sirva de las ventajas de la legitimación nacional -y se convierte en nación política, con todo los ropajes democráticos que ello implica-, mientras que las naciones competitivas con la nación que se yuxtapone al Estado son incardinadas en la categoría de naciones culturales -con las servidumbres ideológicas que ello acarrea: muy concretamente su asimilación con la barbarie, la xenofobia, el fanatismo, la limpieza étnica, etc.-. Idénticas pretensiones son las que guían este redescubrimiento de la patria. La patria aparece ahora como un sanísimo sentimiento afectivo propio del pensamiento republicano y, por supuesto, volcado sobre una comunidad definida en términos de pertenencia estatal, mientras que la nación representa una relación semi-tribal que da lugar, a lo sumo, a una especificidad cultural que debe ser respetada -hay que reconocer que el nacionalismo de Estado, al que se debiera llamar imperialismo, sin ambages, se muestra en los últimos tiempos muy tolerante y munífico a este respecto-. En esta comedia el patriotismo es la abnegada heroína de la obra y el nacionalismo su hermana asilvestrada.

Este trabajo ha intentado mostrar que la acogida del cuño habermasiano es simplemente ideológica. El patriotismo constitucional no es sólo una teoría que muchas veces se cita sin conocer y otras tergiversándola: es la importación de un símbolo retórico, de una consigna. Con qué facilidad se pasa del patriotismo de la CONSTITUCIÓN al PATRIOTISMO de la constitución. La construcción de Habermas bien pudiera tener acomodo en la realidad política -que no jurídica- del Estado español, siempre y cuando se reconociese el derecho de autodeterminación, que es precisamente lo que se trata de evitar con el patriotismo de la constitución en su versión castiza. Hay que tener muchísima prevención con las importaciones teóricas. Desde luego, no queremos decir con ello que no se puedan adquirir teorías en el extranjero. Lo que sucede es que la intelectualidad española suele comprar en la sección de oportunidades. 


\section{Bibliografía}

Ariel del VAL, F. (1993): “Identidades políticas y violencia político-cultural”. Claves de Razón Práctica, $\mathrm{n}^{\circ} 38$.

Álvarez Junco, J. (2001): Mater Dolorosa. La idea de España en el siglo XIX. Madrid: Taurus.

BANDRÉs, J. Ma (1988): "La violencia en la política”. Leviatán, no 34.

BASTIDA, X. (1998): La nación española y el nacionalismo constitucional. Barcelona: Ariel.

Bastida, X. (2002): "La identidad nacional y los Derechos Humanos". En M. Calvo (coord.) Identidades culturales y Derechos Humanos. Madrid: Dykinson.

BAstida, X. (2003): "La constitución vertical. El constitucionalismo y la cuestión nacional". En prensa.

Blas Guerrero, A. DE (1984): Nacionalismo e ideologías políticas contemporáneas. Madrid: Espasa Calpe.

Blas Guerrero, A. De (1989): Sobre el nacionalismo español. Madrid: Centro de Estudios Constitucionales, Cuadernos y Debates, $\mathrm{n}^{\mathrm{o}} 15$.

Blas Guerrero, A. de (1992): "Los nacionalismos españoles y el Estado autonómico". Documentación Administrativa, $\mathrm{n}^{\circ}$ 232-233.

Blas Guerrero, A. De (2001): "España: "Mater dolorosa". Nación y nacionalismo en el siglo XIX”. Claves de Razón Práctica, nº 118.

BuEno, G. (1999): España frente a Europa. Barcelona: Alba Editorial.

Castoriadis, C. (1998a): El ascenso de la insignificancia. Madrid: Ediciones Cátedra.

CAstoriadis (1998b): Los dominios del hombre. Barcelona: Gedisa.

Colom González, F. (1996): "Lealtades compartidas, lealtades divididas: la pertenencia política en Estados plurinacionales". En Isegoría, n $^{\circ} 14$.

Durkheim, E. (1993): Las formas elementales de la vida religiosa. Madrid: Alianza Editorial.

Finkielkraut, A. (1990): La derrota del pensamiento. Barcelona, Anagrama.

García Amado, J. A. (1996): “¿Ductilidad del derecho o exaltación del juez? Defensa de la ley frente a (otros) valores y principios". Anuario de Filosofia del Derecho, Nueva Época, XIII-XIV.

García Trevijano, A. (1994): Del hecho nacional a la conciencia de España o El discurso de la República. Madrid: Temas de Hoy.

Gellner, E. (1988): Naciones y nacionalismo. Madrid, Alianza Universidad.

Gellner, E. (1994): Posmodernismo, razón y religión. Barcelona: Paidós.

Gomberg, P. (1994): “Universalism and Optimism”. En Ethics, no 104.

Habermas, J. (1988): Teoría de la acción comunicativa, 2 vols.. Madrid: Taurus.

HABERMAS, J. (1989): Identidades nacionales y postnacionales. Madrid: Tecnos.

Habermas, J. (1991): La necesidad de revisión de la izquierda. Madrid: Tecnos.

Habermas, J. (1994): "Ciudadanía e identidad nacional. Consideraciones sobre el futuro europeo". En Debats, no 49.

Habermas, J. (1997): Más allá del Estado nacional. Madrid: Trotta. 
Habermas, J. (1998): Facticidad y validez. Sobre el derecho y el Estado democrático de derecho en términos de teoría de discurso. Madrid: Trotta.

Habermas (2000): La constelación posnacional. Barcelona: Paidós.

Hastings, A. (2000): La construcción de las nacionalidades. Cambridge: CUP.

Herrero y Rodríguez de Miñón, M. (1998): "Reglas de ocasión”. El País, 19 de septiembre de 1998.

Hobsbawm, E. (1994): "Identidad". Revista Internacional de Filosofia Política, n 3.

Kedourie, E. (1985): Nacionalismo. Madrid: Centro de Estudios Constitucionales.

LABORda Martín, J. J. (1992): "Patriotismo constitucional y Estado democrático". Sistema, $\mathrm{n}^{\circ} 108$.

LaCASTA ZaBAlZA, J. I. (1998): España Uniforme. El pluralismo enteco y desmemoriado de la sociedad española y de su conciencia nacional e intelectual. Pamplona: Pamiela.

Lacasta Zabalza, J. I. (1999): "Tiempos difíciles para el patriotismo constitucional español". Actas de las XVII Jornadas de la Sociedad española de Filosofía Jurídica y Política. Valencia: Universitat de València.

Lacasta Zabalza, J. I. (2000): "La vulnerable cultura del actual nacionalismo constitucional español". Boletim da Faculdade de Dereito de Coimbra, Studia Iuridica, $\mathrm{n}^{\circ} 48$.

LENK, K. (1982): El concepto de Ideología. Comentario crítico y selección sistemática de textos. Buenos Aires: Amorrortu editores.

López Calera, N. (1995): El nacionalismo, ¿culpable o inocente? Madrid: Tecnos.

LuKÁCs, G. (1968): El asalto a la razón. Barcelona: Grijalbo.

MacCormick, N. (1994): “¿Es filosóficamente creíble el nacionalismo?”. En: Anales de la Cátedra Francisco Suárez, no 31.

MoscA, G. (1982): "La fórmula política”. En El concepto de Ideología, K. Lenk (comp.)

Nathanson, S. (1989): "In Defense of "Moderate Patriotism"”. En Ethics, no 99.

Pérez Tapias, J. A. (2000): "Identidades sin fronteras? Identidades particulares y derechos humanos universales". En P. Gómez García (coord.), Las ilusiones de la identidad, Madrid: Cátedra.

PIQué, J. y SAN Gil, M. (2002): El patriotismo constitucional. Ponencia presentada en el XIV congreso nacional del Partido Popular.

Rodríguez Uribes, J. M. (2002): Formalismo ético y constitucionalismo. Valencia: Tirant lo Blanch

Rosales, J. M. (1997): Patriotismo, Nacionalismo y Ciudadanía: en Defensa de un Cosmopolitismo Cívico. Bogotá: Universidad Externado de Colombia.

Ruipérez, J. (1995): Constitución y autodeterminación. Madrid: Tecnos.

Rusconi; G. E. (1994): "Racionalidad política, virtud cívica e identidad nacional”. En Debats, $\mathrm{n}^{\circ} 49$.

SÁnchez de León, M. (1978): “Trozos de Esapaña”. En Constitución, economía y regiones. Madrid: Siglo Veintiuno.

SeArle, J. (1997): La construcción de la realidad social. Barcelona: Paidós. 
Solé Tura, J. (1985): Nacionalidades y nacionalismos en España. Autonomías federalismo, autodeterminación. Madrid: Alianza Editorial.

SolozÁbal, J. J. (2000): "Desgarros imaginarios”. El Pais, 11 de octubre de 2000.

SLOTERDIJK, P. (1989): Crítica de la razón cínica. Madrid: Taurus.

Sмiтн, A. (1976): Nationalist Movements. Londres: Macmillan.

Sмith, A. (1994): “Tres conceptos de nación”. Revista de Occidente, nº 161.

TAmir, Y. (1993): Liberal Nationalism. Princeton: Princeton University Press.

TAYLOR, Ch. (1992): Multiculturalism and "The politics of Recognition". Princeton: Princeton University Press.

Trabajos Parlamentarios de la Constitución (TP) (1980): Madrid: Publicaciones de las Cortes Generales, 4 tomos.

VILAR, P. (1982): Hidalgos, amotinados y guerrilleros. Barcelona: Crítica.

VILAR, R. (2002): "patriotismo constitucional ou rearme españolista”. Terra e Tempo, $\mathrm{n}^{\circ} 20-21$

VIroli (2000): Por amor a la Patria. Madrid: Acento Editorial

VIROLI (2001): "El sentido olvidado del patriotismo republicano". Isegoría, no 24

Zagrebelsky, G. (1995): El Derecho dúctil. Ley, Derechos, Justicia. Madrid: Trotta. 